\title{
IMPLEMENTASI KEBIJAKAN BRIGADE SIAGA BENCANA DALAM TANGGAP DARURAT DI KABUPATEN BANTAENG
}

\author{
IMPLEMENTATION OF DISASTER ALERT BRIGADE POLICY IN \\ EMERGENCY RESPONSE IN BANTAENG
}

\author{
A.M. Azhar Aljurida1, Muhammad Zulkifli ${ }^{2}$ \\ ${ }^{1}$ Universitas Indonesia Timur, Indonesia \\ ${ }^{2}$ STISIP 17-8-1945 Makassar, Indonesia \\ Email : azharaljurida51@gmail.com
}

\begin{abstract}
The Disaster Preparedness Brigade in the emergency response in Bantaeng district as one of the policy products made by the Bantaeng district government aims to provide health services to the public quickly, precisely and efficiently. The research method used in this study is a qualitative descriptive method, which is to describe and fully describe the information obtained. The results showed that the implementation of policies from the theoretical approach of van Meter and van Horn implementation showed that the disaster alert Brigade aims to bring closer and accelerate health care to the community carried out by special and skilled task force who are on standby 24 hours a day. Natural conditions in Bantaeng Regency especially in terms of geography and topography, sometimes causing delays in handling health for the community, the Bantaeng district disaster preparedness Brigade has the main task of carrying out part of the duties of the health service and hospitals in the context of providing emergency health services or prehospital health care.
\end{abstract}

Keywords: Policy Implementation; Emergency Response; Disaster Alert Brigade.

\begin{abstract}
ABSTRAK
Brigade Siaga Bencana dalam tanggap darurat di Kabupaten Bantaeng sebagai salah satu produk kebijakan yang dibuat oleh Pemerintah Kabupaten Bantaeng bertujuan untuk memberikan layanan kesehatan kepada masyarakat secara cepat, tepat dan efisien. Metode penelitian yang digunakan dalam kajian ini adalah metode deskriptif kualitatif, yaitu mendekripsikan dan menggambarkan secara utuh informasi yang diperoleh. Hasil penelitian menujukkan bahwa implementasi kebijakan dari pendekatan teori implementasi van Meter dan van Horn menunjukkann bahwa Brigade Siaga Bencana bertujuan untuk mendekatkan dan mempercepat penanganan kesehatan kepada masyarakat yang dilaksanakan oleh satgas khusus dan terampil yang siaga selama 24 jam penuh. Faktor kondisi alam yang ada di Kabupaten Bantaeng terutama dari aspek geografi dan topografi, terkadang menjadi penyebab keterlambatan penangan kesehatan bagi masyarakat, Brigade Siaga Bencana Kabupaten Bantaeng mempunyai tugas pokok melaksanakan sebagian tugas Dinas Kesehatan dan rumah sakit dalam
\end{abstract}

Journal of Governance and Local Politics (JGLP)

ISSN (online): 2684-9992, Vol. 1, No. 2, November 2019 
rangka menyelenggarakan pelayanan kesehatan yang bersifat darurat atau penangan kesehatan pra rumah sakit.

\section{Kata kunci: Implementasi Kebijakan; Tanggap Darurat; Brigade Siaga Bencana}

\section{PENDAHULUAN}

Sebuah fakta yang tidak dapat dipungkiri di era pemerintahaan saat ini, telah begitu banyak kebijakan dan program yang dibuat oleh pemerintah baik di tingkat pusat maupun di tingkat daerah, sasaranya pun bermacammacam mulai dari produk kebijakan yang ditujukan untuk mengaplikasan program-program nasional yang telah ditetapkan, hingga pada inisiatif pemerintah untuk menangani masalah yang bersifat teknis operasional. Namun yang terjadi, kebijakan yang lahir bukan menyelesaikan masalah dengan baik akan tetapi justru malah menjadi masalah baru. Seperti bertambahnya beban pembiayaan pemerintah, dan daftar tugas yang harus dikerjakan.

Saat ini, produk kebijakan yang dibuat oleh pemerintah masih memiliki wajah yang memprihatinkan, ditandai masih seringnya ditemukan adanya tumpang tindih kebijakan, prosedur yang tidak tepat hingga pada fenomena over regulation. Padahal dalam pandangan teori menurut mustopadidjaja (2002) kebijakan publik adalah suatu keputusan yang dimaksudkan untuk tujuan mengatasi permasalahan yang muncul dalam suatu kegiatan tertentu yang dilakukan oleh instansi pemerintah dalam rangka penyelenggaraan pemerintahan.

Di sisi lain, pemerintah sebagai penyelenggara negara diwajibkan untuk membuat produk yang dapat memenuhi kebutuhan warga negara sebagaimana diamanatkan dalam Undang-Undang Dasar 1945 dalam pasal 28C ayat 1, menuangkan salah satu hak yang dimiliki oleh warga negara yaitu hak untuk dipenuhi kebutuhan dasarnya demi meningkatkan kualitas hidupnya.

Brigade Siaga Bencana (BSB), merupakan salah satu kebijakan pemerintah kabupaten berdasarkan SK Bupati Bantaeng 
No.430/595/XII/2009 Tentang Pembentukan Tim Emergency Service Kabupaten Bantaeng, sebagai program pemberian layanan emergency atau darurat bagi masyarakat di Kabupaten Bantaeng, konsep ini adalah bentuk mendekatkan layanan dasar yang bersifat darurat, khususnya bagi daerah pegunungan dan pinggiran kota yang membutuhkan waktu untuk menjangkau pusat pelayanan.

Sejak terbentuk pada tanggal 7 Desember 2009, Brigade Siaga Bencana Kabupaten Bantaeng telah menunjukkan eksistensinya sebagai yang terdepan dalam memberikan penanganan tanggap darurat dalam penanganan bencana. Dalam hal pendefinisian, satuan kerja Brigade Siaga Bencana (BSB) mendefinisikan bencana sebagai keadaan darurat bagi manusia yang perlu ditangani dan dianggap darurat, seperti kebakaran, kecelakaan, penyakit dan musibah lainya yang dialami oleh masyarakat, pada intinya membutuhkan penanganan secara sistematis.

Tim Emergency Service yang tergabung dalam Brigade Siaga Bencana disiapkan oleh Pemerintah Kabupaten Bantaeng merupakan salah satu program inovasi sektor pelayanan kesehatan bagi masyarakat. Inovasi tersebut merupakan inisiasi dari Bupati Bantaeng, Nurdin Abdullah untuk menjawab kebutuhan masyarakat sebagai bantuan sosial dan juga pengejawantahan tugas-tugas pemerintahan. Dari aspek tujuan penting hadirnya Brigade Siaga Bencana telah menjadi salah satu terobosan yang sangat berharga bagi masyarakat Kabupaten Bantaeng maupun Indonesia.

Apresiasi pemerintah pusat terhadap inovasi pemerintah Kabupaten Bantaeng dibuktikan dengan adanya pujian dari Menteri Kesehatan RI yang ditindak lanjuti dalam bentuk penghargaan untuk kategori layanan publik bidang kesehatan pada "Anugerah Otonomi Award 2011 oleh The Fajar Institute of Pro-Otonomi (Antaranews.com). Olehnya itu, kehadiran BSB, yang bermula dari keputusan bupati harus ditingkatkan kapasitasnya dengan menyiapkan pilar-pilar untuk menjaga keberlanjutannya, baik dari aspek ketersediaan payung hukum di tingkat daerah, sarana dan prasarana hingga 
pada peningkatan skill aparatur pemerintah yang tergabung dalam satuan kerja tersebut.

Pada sektor kebijakan, Brigade Siaga Bencana telah di desain sebagai komponen yang diharapkan dapat menjadi ujung tombak dalam penanganan bencana dilapangan, yang diharapkan dapat memberikan unsur pelayanan kesehatan pra rumah sakit maupun unsur pelayanan rumah sakit secara cepat yang bertujuan mengurangi angka kematian dan angka kecacatan korban bencana hal ini dapat kita lihat setiap tahunnya Angka Kematian Ibu sampai 200 kasus dan angka kematian bayi sebanyak 165 kasus, namun sejak adanya kebijakan Brigade Siaga Bencana kasus-kasus tersebut terus menurun secara drastis, khusus untuk penanganan kasus lain seperti banjir dan kebakaran kesigapan tim emergency service tersebut selalu menjadi yang terdepan dalam penangan.

Fakta empiris menujukkan bahwa dalam penanganan bencana banyak faktor yang menyebabkan korban meninggal atau cacat disebabkan karena penanganan yang tidak maksimal. Faktor tersebut meliputi kesiagaan masyarakat, atau kesadaran masyarakat untuk mengambil peran dalam penanganan, seperti pemberian informasi dan kordinasi kepada pusat pelayanan juga, lemahnya sistem kerja sama antar tim multidisiplin dalam penanganan tanggap darurat, seperti masih terkotak-kotaknya pada tanggung jawab masing-masing. Hal ini dapat menyebabkan terjadinya kegagalan dalam implementasi kebijakan. Pada dasarnya kehadiran Brigade Siaga Bencana di Kabupaten Bantaeng dapat mengalami kegagalan kebijakan (policy failure) apabila dilihat dalam dua kategori, yaitu kebijakan yang tidak terimplementasikan (non-implementation) dan implementasi yang tidak berhasil (unsuccessful implementation). Tidak terimplementasi mengandung arti bahwa suatu kebijakan tidak dilaksanakan sesuai rencana, hal ini bisa disebabkan karena pihak-pihak yang terlibat di dalam pelaksanaannya tidak mau bekerjasama. Implementasi yang tidak berhasil biasanya terjadi manakala suatu kebijakan dilaksanakan sesuai rencana, 
namun mengingat kondisi eksternal ternyata tidak menguntungkan (misalnya karena pergantian kekuasaan, bencana alam dan sebagainya) kebijakan tersebut tidak berhasil dalam mewujudkan dampak atau hasil akhir yang dikehendaki.

Dalam beberapa kasus yang terjadi seringkali kebijakan mengalami kegagalan disebabkan karena faktor politik, yaitu menyangkut siapa yang mendapatkan apa dari kebijakan tersebut atau antara pihak pelaksana tidak dapat bekerjasama secara efektif, hinggga faktor pergantian kekuasaan yang memodifikasi kebijakan sehingga tidak lagi sesuai dengan perencanaan pada awalnya.

\section{METODE PENELITIAN}

Sesuai dengan permasalahan yang diangkat dalam penelitian ini, maka dalam penelitian ini penulis menggunakan jenis penelitian deskriptif dengan pendekatan kualitatif. Penelitian tersebut digunakan untuk mengeksplorasi (menemukan) dan menjelaskan fenomena yang sedang terjadi dalam masyarakat. Penelitian deskriptif adalah penelitian yang berupaya mengungkapkan suatu masalah dan keadaan sebagaimana adanya, untuk itu peneliti dibatasi hanya mengungkapkan fakta-fakta dan tidak menggunakan hipotesa.

\section{HASIL DAN DISKUSI}

Brigade Siaga Bencana (BSB) resmi terbentuk pada tanggal 7 Desember 2009, melalui SK Bupati Bantaeng No. 430/595/XII/2009, Tentang Pembentukan Tim Emergency Service Kabupaten Bantaeng, bertepatan dengan ulang tahun Kabupaten Bantaeng yang ke 755, kebijakan ini memiliki tujuan untuk mendekatkan pemberian layanan kesehatan kepada masyarakat dengan cepat, mudah dan tepat sasaran. respon cepat dalam penangan kasus merupakan karateristik dari tim BSB, sehingga tidak 
berlebihan apabila satuan ini merupakan salah satu andalan pemerintah Kabupaten Bantaeng pada bidang pelayanan publik.

Dalam optimalisasi pelakasanaan tugas oleh Dinas Kesehatan Kabupaten Bantaeng sebagai penanggung jawab umum membentuk struktur dan garis komando BSB, yang ditetapkan berdasarkan keputusan Kepala Dinas Kesehatan Kabupaten Bantaeng Nomor 1241/440.1-2.4/2009 Tentang Penetapan Prosedur Tetap (Protap) Pelayanan pada Brigade Siaga Bencana Kabupaten Bantaeng tanggal 7 Desember 2009. Pembentukan BSB sendiri, didasari oleh begitu banyaknya kasus-kasus emergency yang dialami oleh masyarakat, khususnya pada wilayah pinggiran kota dan pedesaaan, yang jauh dari pusat layanan kesehatan dan kurangnya keterampilan tenaga kesehatan di tingkat desa serta sulitnya transportasi bagi masyarakat untuk dapat menjangkau layanan kesehatan.

Hal ini dilatari kondisi kewilayahan Kabupaten Bantaeng, yang memiliki kondisi geografi dataran dan daerah pegununan sehingga faktor jarak dan minimnya akses transportasi menjadi faktor penyebab lambatnya penanganan bencana, sehingga peristiwa seperti ini biasanya disertai dengan jatuhnya korban dan bila tidak ditangani dengan tepat akan menghambat, mengganggu dan merugikan masyarakat, Masalah-masalah inilah yang menjadi renungan tersendiri bagi Bupati Bantaeng, Nurdin Abdullah, untuk mencari solusi sehingga diformulasi sebuah langkah strategis untuk membentuk sistem koordinasi antara sektor sebagai tim tanggap darurat, dalam Brigade Siaga Bencana Kabupaten Bantaeng. Posko Pusat Brigade Siaga Bencana berada pada daerah stratregis terletakdi jalan poros provinsi, Jalan Pahlawan No. 55, Kelurahan Bonto Sunggu, Kecamatan Bissappu. pemerintah Kabupaten Bantaeng, melahirkan kebijakan membentuk tim tanggap darurat yang yaitu PSC (Public Safety Center), 119 yang didalamnya tergabung BSB Kabupaten Bantaeng.

Dalam hal pendefenisian Bencana, Pemerintah Kabupaten Bantaeng, menerjemahkan bencana sebagai kondisi musibah yang dialami 
masyarakatnya yang memerlukan pertolongan seperti, orang sakit, melahirkan, kecelakaan dan lain-lain, yang pada dasarnya membutuhkan pertolongan maka Brigade Siaga Bencana menjadi yang terdepan dalam penanganan, yang terpenting adalah tugas Brigade Siaga Bencana adalah memberikan pelayanan dasar kesehatan kepada masyarakat yang membutuhkan, dengan kondisi daerah Kabupaten Bantaeng yang rawan bencana, maka inovasi pemerintaha dalam melahirkan tim emergency service sangat dibutuhkan, dalam perjalanannya hingga saat ini Brigade Siaga Bencana telah sukses menangani jatuhnya korban yang disebabkan karena keterlambatan penanganan.

Salah satu fenomena kebijakan yang akan diamati dalam penelitian ini adalah impelementasi kebijakan Brigade Siaga Bencana dalam tanggap darurat di Kabupaten Bantaeng, dimana posisi kebijakan pembentukan tim emergency service Brigade Siaga Bencana merupakan rangkaian pilihan pemerintah Kabupaten Bantaeng, dalam hal ini pejabat publik yang berkewenangan untuk memformulasi kebijakan dan membuat keputusan bertindak utnuk menangani kejadian gawat darurat yang dialami masyarakat Kabupaten Bantaeng melalui panggilan darurat kepada call center tim emergency service Brigade Siaga Bencana. Serangkaian arah tindakan pemerintah Kabupaten Bantaeng didasarkan pada isu-isu yang strategis aktual dan potensial berdasarkan segmentasi kebutuhan masyarakat di bidang kesehatan.

Pada tataran keputusan bertindak maka Pemerintah Kabupaten Bantaeng, melahirkan kebijakan untuk memecahkan masalah publik di bidang kesehatan yaitu dengan dikeluarkannya Surat Keputusan Bupati Bantaeng Nomor: 430/595/XII/2009 tanggal 1 desember 2009 Tentang Pembentukan Tim Emergency Service dan selanjutnya Dinas Kesehatan Kabupaten Bantaeng sebagai penanggung jawab umum membentuk struktur dan garis komando BSB berdasarkan Keputusan Kepala Dinas Kesehatan Kabupaten Bantaeng Nomor 1241/440.1-2.4/2009 tentang Penetapan 
Prosedur Tetap (Protap) Pelayanan pada Brigade Siaga Bencana Kabupaten Bantaeng tanggal 7 Desember 2009.

Berdasarkan pendapat yang dikemukakan oleh Thomas R Dye bahwa "Public Policy is whatever the government choose to do or not to do", Kebijakan publik adalah apapun pilihan pemerintah untuk melakukan sesuatu atau tidak melakukan sesuatu (Nugroho, 2004). Dengan melihat kedudukan, latar belakang dan dasar pembentukan tim emergency service Brigade Siaga Bencana dan teori yang dikemukakan oleh ahli kebijakan Thomas R Dye, dapat dinyatakan bahwa Brigade Siaga Bencana adalah sebuah produk kebijakan publik yang dibuat oleh pejabat publik yang berwenang yaitu pemerintah Kabupaten Bantaeng.

Selanjutnya penelitian ini akan menjabarkan salah satu tahap dalam analisis kebijakan publik yaitu tahapan implementasi, untuk memperoleh temuan penelitian berdasarkan permasalahan yang diangkat dalam penelitian ini maka, digunakan teori impelementasi kebijakan yang dikemukakan oleh van Meter dan van Horn, dimana menurutnya implementasi kebijakan dipengaruhi oleh beberapa faktor yaitu : 1) standar dan tujuan kebijakan (standar and objectivity),; 2) sumberdaya (resource); karakteristik agen pelaksana (the characteristic of the implementing agencies); 4) sikap dan kecenderungan para pelaksana (Disposition); 5) komunikasi antar organisasi dan aktivitas pelaksana (introrganization communication and enforcement activities); dan 6) kondisi lingkungan ekonomi, sosial, dan politik (economic, social and political conditions).

Berikut paparan analisa implementasi kebijakan Brigade Siaga Bencana dalam tanggap darurat di Kabupaten Bantaeng adalah sebagai berikut :

\section{Ketetapan Sasaran dan Tujuan Kebijakan}

Standar dan tujuan kebijakan merupakan faktor yang akan mempengaruhi proses implementasi kebijakan program tim emergency service Brigade Siaga Bencana Kabupaten Bantaeng. Ketidakmenentuan 
standar dan tujuan kebijakan dapat membuat kesulitan bagi implementor untuk memahaminya dan sekaligus dapat memunculkan keragaman pada disposisi (kecenderungan implementor untuk melaksanakan kebijakan) berbagai aktor yang terlibat dalam proses implementasi, kondisi ini akhirnya akan kurang mendukung kelancaran dan keberhasilan implementasi kebijakan tim emergency service Brigade Siaga Bencana Kabupaten Bantaeng. Dalam penelitian ini peneliti membagi penilaian standar (ukuran-ukuran dasar) dan tujuan program tim emergency service brigade bencana.

Tujuan dilahirkannya program Brigade Siaga Bencana, apabila dilihat dari sisi dasar hukum pelaksanaannya sesuai dengan Undang Dasar 1945 pasal 28 ayat 1 dimana dinyatakan bahwa : "Salah Satu Hak Dasar Rakyat adalah Hak Untuk Memperoleh Pelayanan Kesehatan” dengan mengambil kebijakan bahwa pelayanan kesehatan merupakan hak warga Negara Indonesia, yang selanjutnya secara teknis diterjemahkan melalui Keputusan Menteri Kesehatan RI Nomor 462 Tahun 2002 tentang Safe Community. Kebijakan pemerintah inilah yang diharapkan mampu memperbaiki derajat kesehatan masyarakat.

Pemerintah Kabupaten Bantaeng di bawah kepimpinan Bupati Bantaeng Nurdin Abdullah mengacu kepada tujuan nasional dan kebutuhan masyarakat Kabupaten Bantaeng maka dilahirkanlah kebijakan program Brigade Siaga Bencana, apabila dilihat dari tujuan terbentuknya Brigade Siaga Bencana merupakan jawaban atas persoalan yang terjadi selama beberapa tahun terakhir, yaitu pada kurun waktu 5 (lima) tahun, yaitu sejak tahun 2005 sampai dengan tahun 2009 terlihat angka kematian ibu melahirkan dan Angka kematian kasar tetap menduduki posisi teratas, hal ini menjadi pekerjaan rumah (PR) bagi pemerintah Kabupaten Bantaeng.

Dari hasil analisis wawancara informan, dapat dijelaskan bahwa tujuan dibentuknya kebijakan Program Brigade Siaga Bencana disebabkan karena adanya masalah pubik di bidang kesehatan sehingga mendorong pemerintah untuk mengintervensi persoalan dengan memformulasikan 
kebijakan agar terselesaikannya masalah publik. Fungsi penting dari program ini telah dirasakan oleh masyarakat, berdasarkan analisis wawancara informan diperoleh informasi bahwa subtansi tujuan pemerintah untuk melahirkan program kebijakan yang ditujukan untuk memberikan respon cepat kepada kejadian bencana telah sesuai dengan harapan masayarakat, juga terlihat adanya kepercayaan masyarakat yang cukup baik terhadap kemampuan petugas BSB dalam menangani masalah mereka.

\section{Sumber Daya}

Van Meter dan van Horn Mengemukakan sumber daya kebijakan juga menjadi salah satu faktor penting yang menunjang keberhasilan sebuah kebijakan, kurang tersedianya sumber daya yang dibutuhkan memberikan kontribusi terhadap kegagalan kebijakan, karena bagaimanapun jelas dan konsistennya ketentuan-ketentuan atau aturan-aturan suatu kebijakan, jika para personil yang bertanggung jawab untuk mengimplementasikan kebijakan kurang mempunyai kemampuan untuk melakukan pekerjaan secara efektif, maka implementasi kebijakan tersebut tidak akan bisa efektif berdasarkan pernyataan tersebut maka ketersediaan sumber daya.

Pada dimensi ini indikator yang dinilai adalah kemampuan petugas BSB dalam menjalankan tugas yang diberikan oleh organisasi, apakah dari segi latar belakang keahlian petugas menunjang kinerjanya pada organisasi dan apakah ketersediaan jumlah pegawai dapat memenuhi kebutuhan organisasi.

Sumber daya manusia yang bertugas pada Brigade Siaga Bencana adalah sumber daya manusia yang telah diseleksi dan memiliki keahlian pada bidangnya masing-masing, bahwa dari segi jumlah maupun keahlian SDM yang bertugas pada tim BSB, dianggap telah cukup memadai, dari segi jumlah personil dengan prosedur kerja tim BSB dinilai sudah seimbang, mengingat posisi BSB adalah arus lalu lintas penanganan pra rumah sakit sehingga tidak begitu banyak membutuhkan personil jika dibandingkan dengan unit pelayanan kesehatan lainnya. Dari segi keahlian personil yang bertugas pada 
BSB, tim dokter, perawat, sopir, dll, dari informasi diatas dianggap tidak masalah, ukuran dari kemampuan personil dapat dilihat dari kemampuannya menjalankan pekerjaan juga sertifikat keahlian dan pelatihan yang telah diikuti.

Tabel 1.

Personil Tim BSB Kabupaten Bantaeng

\begin{tabular}{|c|l|c|}
\hline No & \multicolumn{1}{|c|}{ Jenis Tenaga } & Jumlah Tenaga \\
\hline \hline 1 & Dokter bersertifikat (ATLS, ACLS, GELS/SPGDT, EKG & 20 \\
2 & Perawat bersertifikat (BTCLS) & 26 \\
3 & Sopir terlatih (MFR) & 6 \\
4 & Cleaning Service terlatih (MFR) & 2 \\
\hline \multicolumn{2}{|c|}{ Jumlah } & 54 \\
\hline
\end{tabular}

Data Sekunder: Tahun 2016

Selain faktor sumber daya manusia, faktor pendanaan juga menjadi sumber daya yang sangat penting untuk menunjang implementasi program BSB Kabupaten Bantaeng, ketersediaan dana yang cukup untuk menunjang operasional kegiatan akan mendukung kelancaran pelakasanaan tugas Brigade Siaga bencana, berikut kondisi penganggaran BSB dari tahun ke tahun yang berasal dari Pemerintah Kabupaten Bantaeng.

Anggaran tersebut digunakan untuk membayar insentif dokter, perawat, sopir, dan petugas kebersihan; biaya operasional kendaraan (bahan bakar, oli, dan lain-lain); dan biaya makan minum petugas jaga. Selain bersumber dari APBD, pembiayaan Brigade Siaga Bencana juga didukung oleh JAMKESDA (Program Layanan Kesehatan Gratis) dan Jaminan Kesehatan Nasional (JKN) yang diselenggarakan oleh BPJS Kesehatan per 1 Januari 2014.

Tabel 2.

Kondisi Penganggaran BSB dari Tahun ke Tahun

\begin{tabular}{|c|c|l|}
\hline No & Tahun & \multicolumn{1}{|c|}{ Jumlah anggaran } \\
\hline 1 & 2010 & Rp. 981.6 Juta \\
\hline 3 & 2011 & Rp. 1 Milyar \\
\hline
\end{tabular}




\begin{tabular}{|c|c|l|}
4 & 2012 & Rp. 1,5 Milyar \\
\hline 5 & 2013 & Rp.2,5 Milyar \\
\hline
\end{tabular}

Data Sekunder: Tahun 2016

Dari analisis hasil wawancara diperoleh informasi bahwa sumberdaya anggaran yang dibutuhkan oleh brigade siaga bencana, dialokasikan melalui Dinas Kesehatan yang juga merupakan penanggung jawab program, sehingga kebutuhan-kebutuha organisasi BSB berasal dari anggaran dinas kesehatan.

\section{Karakteristik Badan Pelaksana}

Berdasarkan teori implementasi pada dimensi kareteristik badan pelaksana, maka kompentensi staf dan dukungan dari para personil pelaksana program Brigade Siaga Bencana dalam implementasi kebijakan, merupakan salah satu unsur yang spesifik mempengaruhi keberhasilan implementasi program, indikatornya adalah dukungan politik dari eksekutif dan legislatif, dan hubungan pelaksana dengan pembuat keputusan.

Dari hasil analisis wawancara diketahui bahwa bentuk dukungan pemerintah kabupaten terhadap program ini cukup memadai baik dari sisi anggaran maupun kebutuhan yang diperlukan oleh BSB dalam menjalankan tugas, kehadiran tim emergency service dirasakan membawa dampak yang cukup signifikan terhadap derajat kesehatan masyarakat. Keberhasilan tim BSB menekan jumlah korban jiwa karena keterlambatan penangan, melahirkan kepercayaan bagi eksekutif maupun legislatif untuk terus memaksimal fungsi program ini, selain itu menjadikan BSB sebagai salah satu program unggulan diKabupaten Bantaeng merupakan dukungan dari pemerintah sebagai program yang harus terus dikembangkan. Pada indikator hubungan pelaksana dengan pembuat kebijakan pada program Brigade siaga bencana, hubungan yang dimaksud disini adalah kaitan secara formal antara pelaksana kebijakan dengan pembuat kebijakan.

Dari hasil analisis wawancara diatas diperoleh informasi bahwa kaitan formal antara pembuat kebijakan (policy maker), dengan para pelaksana kebijakan (implementor), memiliki kaitan yang sangat erat, posisi 
bupati Bantaeng sebagai kepala daerah yang juga merupakan penanggung jawab pembangunan adalah inisiator dari lahirnya program BSB ini, kaitan ini memberikan dampak (impact), positif terhadap keberhasilan program, pada fakta lain ditemukan informasi bahwa beberapa fasilitas penunjang operasional kegiatan BSB, yaitu ambulance modern yang berasal dari bantuan CSR pemerintah jepang dan juga Bank Sulsel, atas dasar kerjasama dari Bupati Bantaeng selaku pembuat kebijakan (policy maker). Sehingga pada dimensi dimensi hubungan dan keterkaitan antara pembuat kebijakan dengan para pelaksana kebijakan dapat dikatakan sudah cukup baik dan menunjang terimlementasinya program ini.

\section{Kondisi Lingkungan, Sosial dan Ekonomi}

Van Meter dan van Horn menyatakan bahwa sukses tidaknya implementasi kebijakan juga dipengaruhi oleh kondisi-kondisi lingkungan ekonomi dan sosial, Dukungan dan penolakan dari lembaga eksternal. Jika lembaga eksternal mendukung, maka pelaksanaan kebijakan-kebijakan akan berhasil. Sebaliknya, jika menolak maka kebijakan akan gagal. Oleh karena itu, agar sukses, pengambil kebijakan dan para pelaksananya harus melakukan penyamaan visi dan persepsi dalam kebijakan yang diambil.

Pada dimensi ini dukungan kuat terhadap keberhasilan program Brigade Siaga Bencana terletak pada modal sosial yang dimiliki oleh bupati Bantaeng Nurdin Abdullah selaku inisiator dari brigade siaga bencana, kepercayaan masyarakat dan kelompok sosial politik kepada keberhasilankeberhasilan program terdahulu memberikan kontribusi positif terhadap inovasi yang sedang dikembangkankan.

Dari analisis hasil wawancara di atas diperoleh informasi bahwa pemerintah kabupaten, dalam hal ini bupati Bantaeng memiliki modal sosial dan reputasi yang cukup baik dimata masyarakat dan kelompok sosial sehingga dukungan senantiasa diberikan apabila ada program-program yang masih baru, terutama program untuk yang berbasis kebutuhan masyarakat. 
Keterlibatan kelompok masyarakat dalam mendukung program BSB, terlihat pada sektor ketenagaan BSB, dimana tokoh masyarakat tokoh agama dan kelonmpok forum jaringan serta ormas seperti Fatayat NU, berpartisipasi secara langsung untuk mendukung program ini. Dari hasil analisis wawancara ini diperoleh informasi, bahwa program BSB ini mendapat dukungan dari kelompok-kelompok masyarakat disebabkan karena adanya kepercayaan kepada pemerintah bahwa program tersebut memang dibutuhkan oleh masyarakat.

\section{KESIMPULAN}

Brigade Siaga Bencana Kabupaten Bantaeng mempunyai tugas pokok melaksanakan sebagian tugas dinas kesehatan dan rumah sakit dalam rangka menyelenggarakan pelayanan kesehatan yang bersifat darurat atau penangan kesehatan pra rumah sakit, tugas ini ditujukan agar tidak ada jatuh korban yang disebabkan karena keterlambatan penanganan, tim Brigade Siaga Bencana setelah mendapatkan informasi pengaduan dari masyarakat dengan secepat mungkin mendatangi lokasi tujuan dan melakukan pemeriksaan langsung kepada pasien dan kemudian menentukan tindakan diberikan. Petugas kesehatan yang ditempatkan pada brigade siaga bencana, adalah petugas yang berada dibawah naungan dinas kesehatan, hal ini berdasarkan SK Bupati Bantaeng Nomor 430/595/XII/2009 tanggal 1 Desember 2009 tentang pembentukan tim emergency service, yang menempatkan Kepala Dinas Kesehatan sebagai salah satu penanggung jawab organisasi. Armada kesehatan maka salah satu keandalan tim emergency service Brigade Siaga Bencana terletak pada armada yang dimiliki, sopir yang terlatih dan armada ambulane yang didukung oleh sarana modern bertekhnologi tinggi menjadi penunjang keberhasilan tim BSB. 


\section{REFERENSI}

Abdul Wahab, Solichin. 1997. Analisis Kebijakan Publik dari Formulasi ke Implementasi Kebijaksanaan Negara, Jakarta. Bumi Aksara.

Anugrah Otonomi Award, 2011. The Fajar Institute of Pro-Otonomi. (Antaranews.com).

Bantaeng Dalam Angka. Badan Pusat Statistik Kabupaten Bantaeng Tahun 2016.

Dunn, Willian.N. 2000. Pengantar Analisis Kebijakan Publik. Diterjemahkan oleh: Samodra Wibawa, dkk. Jogjakarta: Gajah Mada University.

Jones, Charles O. 1996. Pengantar Kebijakan Publik (Public Policy). Diterjemahkan oleh Ricky Ismanto. Jakarta : PT Raja Grafmdo Persada. Kadji, Julianto. 2008. Implementasi Kebijakan Publik Melalui MSN Approach. Jurnal Teknologi dan Manajemen Informatika, Volume 6 Edisi Khusus Juli 2008. Malang : Universitas Merdeka Malang.

MPBI (Masyarakat Penanggulangan Bencana Indonesia). 2005. Membangun Ketahanan Bangsa dan Komunitas Terhadap Bencana, Jakarta MPBI.

Nudgroho D, Riant. 2003. Kebijakan Publik : Formulasi, Implementasi, dan Evaluasi. Jakarta : PT Elex Media Komputindo.

SK Bupati Bantaeng No.430/595/XII/2009 Tentang Pembentukan Tim Emergency Service Kabupaten Bantaeng.

Undang-Undang Dasar 1945 pasal 28C ayat 1. 